\title{
A aura da presença em processos de deslocamento: nas ruínas do playground
}

\author{
The Aura of Presence in Displacement Processes: \\ In the Ruins of the Playground
}

\section{El aura de presencia en los procesos de desplazamiento: en las ruinas del patio de recreo}

Mauricius Martins Farina (Universidade Estadual de Campinas, Brasil) *

https://doi.org/10.22409/poiesis.v21i35.40527

RESUMO: Tendo como questão a ideia do deslocamento entre territórios, consideramos neste texto as obras do mestre português Grão Vasco, dos brasileiros Antônio Francisco Lisboa e Manuel da Costa Ataíde, artistas que colocaram em questão uma ideia de estilo a partir de matrizes e emulações da arte, mas sob o impacto de circunstâncias autóctones. Obras de arte são atmosferas de acontecimento, nelas há algo que não se determina apenas como forma. Questões como circularidade e sobrevivência nos impactam desde suas próprias origens como processos de transformação.

PALAVRAS-CHAVE: transculturalidade; história da arte; patrimônio; Vasco Fernandes; Antônio Francisco Lisboa; Manuel da Costa Ataíde

\footnotetext{
* Mauricius Martins Farina tem pós-doutorado em Artes pela Faculdade de Belas Artes da Universidade do Porto, doutorado em Ciências da Comunicação pela USP. É professor do Instituto de Artes da Universidade Estadual de Campinas. E-mail: mauriciusfarina@gmail.com. Orcid: http://orcid.org/0000-0003-4751-5266
} 
ABSTRACT: Considering the idea of displacement between territories, this text evaluates the works of the Portuguese master Grão Vasco and the Brazilians Antônio Francisco Lisboa and Manuel da Costa Ataíde, artists that brought to the surface an idea of style from matrices and simulations of arts, but under the impact of autochthonous circumstances. Works of arts are atmospheres of happenings, in which there is something that is not determined only as shape. Questions as survival and circularity are impacting us since its own origins as transformation processes.

KEYWORDS: transculturality; history of art; heritage; Vasco Fernandes; Antônio Francisco Lisboa; Manuel da Costa Ataíde

RESUMEN: Teniendo en cuenta la idea del desplazamiento entre territorios, consideramos en este texto las obras del maestro portugués Grão Vasco, de los brasileños Antônio Francisco Lisboa y de Manuel da Costa Ataíde, artistas que cuestionaron una idea de estilo basada en matrices y emulaciones de arte, pero bajo el impacto de las circunstancias autóctonas. Las obras de arte son atmósferas de acontecimiento, en ellas hay algo que no se determina solo como una forma. Cuestiones como la circularidad y la supervivencia nos impactan desde sus orígenes como procesos de transformación.

PALABRAS CLAVE: transculturalidad; história del arte; patrimônio; Vasco Fernandes; Antônio Francisco Lisboa; Manuel da Costa Ataíde

Recebido: 15/11/2019; Aprovado: 5/1/2020

Citação recomendada:

FARINA, Mauricius Martins. A aura da presença em processos de deslocamento: nas ruínas do playground. Poiésis, Niterói, v. 21, n. 35, p. 237-262, jan./jun. 2020.

[https://doi.org/10.22409/poiesis.v21i35.40527]

Mauricius Martins Farina, A aura da presença em processos de deslocamento: nas ruínas do playground. 


\section{A aura da presença em processos de deslocamento: nas ruínas do playground}

\section{Introdução}

O assunto das viagens artísticas é denso, com várias possibilidades de aproximação, a considerar que as relações de deslocamento são próprias à natureza da arte e de sua história, seja a partir das viagens ou sob influência delas. As histórias da arte têm demonstrado a ocorrência de diálogos que se efetuam nas obras a partir de tradições distintas. Podemos dizer que as viagens artísticas acomodam condições próprias para a fundação de novos cenários, e que estes permitem a sobrevivência de culturas antigas, atuando em camadas superpostas de tempo e de espaço, em um complexo campo de contextos históricos, cujos fragmentos podem ser de difícil aproximação.
A possibilidade de intercâmbio entre culturas é assunto próprio às viagens, e se oferece de muitas maneiras, seja pelo deslocamento físico de seus atores ou através de interpostos com a difusão das imagens feitas por processos de mimetismo, a partir de obras consideradas desde uma matriz cultural. Essa condição configura um tipo de conhecimento distante da obra, de sua presença; entretanto, permite a ocorrência de outras, em um encadeamento de procedimentos cuja aproximação é sempre delicada. É de se destacar que há uma correspondência entre as obras de arte, que a fabricação artística como um processo de emulação sempre foi um ponto de referência para história da arte, dos artistas e de seus processos de aprendizagem, seja nas oficinas dos mestres ou nas academias. As- 
sim, uma espécie de viagem pode ser construída a partir de outras imagens que, desde uma matriz cultural, estão sobre a influência de outras; nesse caso, são as imagens, elas mesmas, que viajam.

Nesse constructo das viagens, na possibilidade materializada pela influência de um lugar sobre outro, inúmeras experiências serão percebidas como processos de oportunidade que se colocam ao viajante. As viagens estão marcadas nas obras de muitos artistas viajantes, como atos de presença que se distanciam no tempo, mas como tal estão implicadas em um ambiente turvado de esquecimentos. Mesmo assim, uma parcela dessa história sobrevive nos enunciados que se pode perceber como parte de outros sintomas.

Existem muitas aberturas para uma investigação sobre tais causas relação e, para situar algo, pensamos, por exemplo, na influência que o artista flamengo Peter Paul Rubens (1577-1640) exerceu sobre outros artistas a partir de suas viagens. Rubens, tendo feito inúmeras viagens e morado em diversos lugares, aprofundou o seu círculo de relações públicas, incluindo-se o fato de ter se tornado embaixador e, por essa razão, poder fre- quentar várias cortes europeias onde sua influência sobre outros artistas, entre eles $\mathrm{Di}$ ego Velázquez, é reconhecida. De outra parte, as relações inventivas de Velásquez, um artista que ainda nos convoca a pensar sobre a representação especular na pintura a partir de uma instância narrativa muito própria, demonstra que os diálogos entre os artistas não podem ser reduzidos a meras relações de influência.

A atmosfera da arte de outros séculos, ainda que diante de sombras, nos ajuda a resistir, ou mais, a admitir, pela resiliência, uma espécie de intuição de permanência que é própria da vida em sua efemeridade. Nesse horizonte de deslocamentos, temporais e corporais, a viagem da arte vai se encontrar com ideias e possibilidades renovadas. Existem aquelas que nos interessam mais de perto e, mesmo a temer as interferências míticas dessa distância, elas nos encontram em nossa própria alteridade, a partir de referências que se cruzam de Flandres à Península Ibérica e depois, da Itália com sua renovação da antiguidade clássica.

Há o caso do pintor Vasco Fernandes (1475-1542), conhecido como Grão Vasco,

Mauricius Martins Farina, A aura da presença em processos de deslocamento: nas ruínas do playground. 
cuja produção, de extrema relevância para a história da pintura portuguesa, ainda está, à sua maneira, revestida de sombras. Sabe-se que trabalhou muito proximamente ao pintor nascido em Flandres, de nome Francisco Henriques, que emigrou para Portugal no ano 1500 e que morreu em Lisboa em 1518, vitimado pela peste. Trabalhou com Francisco Henriques e teve outros colaboradores de origem flamenga, mas não se tem registro de que tenha ido a Flandres. Sua viagem a partir da tradição flamenga, em Portugal, nos aproxima de eventos interligados ao gótico como uma matriz cultural que fundamentou a invenção de realidade na representação pictórica. Essa influência entre os Países Baixos e a cultura dos países ibéricos se determinou por uma condição histórica muito específica de sua fundação na instância de um período conhecido como flamejante ou manuelino.

Dois séculos depois, destacamos para pensar, a partir das viagens da conquista e da colonização, a obra de Antônio Francisco Lisboa, que viveu nas Minas Gerais durante o século XVIII. É desnecessário acentuar que a história de vida desse artista se conecta a Portugal, de várias maneiras, seja porque seu pai era português, mestre no ofício da arquitetura e da talha, seja por ser, igualmente, filho de uma escrava forra, o que inclui a matriz africana e suas problemáticas de apagamento do outro. Assim, o mestre mulato, como tantos outros em sua terra, será verticalmente afetado pelas condições de origem. Ficou conhecido com o triste epíteto de "Aleijadinho" pelos problemas físicos que surgiram na maturidade, foi mestre da escultura e da arquitetura, entretanto, sofreu diversas mistificações literárias, no devir de um próprio esquecimento da história do século XVIII em Minas Gerais. Atualmente, contamos com investigações mais científicas sobre sua obra e, ao considerar, com alguma distância, sobretudo o que se disse ou se quis dizer, a partir das informações iniciais de Rodrigo José Ferreira Bretas (1815-1866), que foi o primeiro biógrafo do mestre. Seu trabalho, inspirado por um nacionalismo em construção, moldou a ideia de um herói mulato, um gênio autóctone de Ouro Preto que, apesar de suas desgraças pessoais, consegue construir uma obra monumental. Também os modernistas, liderados por Mario de Andrade, atuaram para a construção dessa ideia de potência original, de uma arte brasileira autêntica. Assim, a figura do mestre Aleijadinho, que será posteriormente intitu- 
lado o "patrono artístico"1 da arte brasileira, irá servir como paradigma de uma matriz de origem para a arte nacional.

As distâncias temporais recobrem as experiências da arte como sombras abertas às interpretações fabuladas, mas isso não justifica projeções sobre a produção artística que passem a desconsiderar aspectos de uma iconologia que se tramou na própria experiência da obra. Entre os enganos evidentes sobre tal coisa, estão os entusiasmos literários que, deturpados ideologicamente, partem na suposição de que determinados artistas são gênios e, como tal, sobrevoam o mundo como mensageiros de uma espécie milagrosa de acontecimentos. O trabalho artístico de Vasco Fernandes, o mestre de Viseu, também foi afetado por interpretações carregadas de falseamentos interpretativos.

Há uma distorção entre o acontecer e o perceber. $\mathrm{O}$ ajuizamento crítico que se impõe em uma obra de arte, se ocorrer por uma projeção desconectada de lugar e de sentido, age sem considerar a viagem e o outro. Se a obra é apropriada pelo interesse imediato de um comentador alheio, nesse caso atuará com mera ilustração e não será reconhecida em sua potência aurática. A mitificação heroica dos artistas não acontece como fato de interesse para a história da arte, mas está marcada por circunstâncias afetadas pela necessidade de afirmação de sujeitos como personagens especiais, nesse caso, o próprio nacionalismo, quando emerge, atua como um espécie de recalque, surgindo como forma de afirmar, diante de circunstâncias de inferioridade, um lugar sobre o qual o marginalizado é especial e, sobretudo, autóctone. Entretanto, é fato que os artistas não trabalham sozinhos, mas se organizam a partir de uma articulação coletiva, indo além do ambiente estabelecido nos termos de uma hegemonia cultural dominante e, muitas vezes, pouco hospitaleira.

De modo contrário ao fetichismo viajante da atualidade, que pode estar situado nas ruínas de um playground cultural, a nomeada economia criativa atua para transformar museus em negócios e inventa grandes exposições que funcionam como paisagens a se admirar sem guardar memórias. Uma viagem que se faz, olhando por espécies escolhidas que estão passando pela janela. Diante das grandes multidões e do espaço moderno, percebemos que a necessidade

Mauricius Martins Farina, A aura da presença em processos de deslocamento: nas ruínas do playground. 
de conhecimento, a partir do outro, da experiência que não se prende ao imediato, deverá seguir para além de circunstâncias que se determinam à conquista de souvenires, ou que se apresentam como crise nas ruínas do conhecimento.

Em um sentido contrário àquele, cuja manipulação de interesses pretende-se como uma espetacularização da arte, transformando seus espaços em "não-lugares", estão demarcados princípios de necessidades expressivas, que são, afinal, aquilo que tratam as questões da arte, a partir dos artistas e das tradições que flutuam como um sentido plural para a vida das culturas. Desse modo, os processos de deslocamento estão incluídos naquilo que se oferece ao outro a partir da obra. Nas camadas superpostas do tempo, os espaços de conexões entre a experiência de memória e a realização das obras se instauram como patrimônio. Pensamos na arte como lugar em trânsito, em diálogo com outros lugares, mas sempre como um lugar a respeito de uma experiência da presença.

\section{Vasco Fernandes e a construção de uma possibilidade}

Conhecer as pinturas de Vasco Fernandes na cidade de Lamego, ao norte de Portugal, não é algo que se faça sem um impacto dessa presença e não apenas em função de sua monumentalidade. Ao inferirmos a partir delas, sobre forte acento de um princípio cromático que nos faz lembrar a pintura flamenga, sabemos, desde logo, que será necessário investigar um pouco mais. Da relação de trabalho entre Grão Vasco e Francisco Henriques é muito provável que possam ter ocorrido conhecimentos específicos sobre tecnologias da pintura flamenga, mas haverá alguma coisa que ultrapassa as fronteiras de uma evidente emulação. Este conjunto poderia de fato estar em qualquer grande museu europeu, pois sua qualidade ultrapassa as fronteiras de uma província. Quando tais pinturas ficam diante de nós, não há como desconsiderar que se existem referências que nos provocam a partir de Flandres, existe também um sentimento que nos insinua uma outra matriz que deriva de Portugal: a emoção. Esse imaginário complexo e relacionado é acionado em nossa própria experiência, quando em um pri- 
meiro contato podemos sentir o que se coloca diante de nossa visão.

O inesperado é mais impactante quando estamos à deriva do conhecido. Estar em contato com essas pinturas do Grão Vasco nos põe a pensar, por um instante, que poderíamos estar em outro sítio, quem sabe em Bruges, em Gante ou mesmo em Bruxelas. Vasco Fernandes, antes de ser o Grande Vasco, trabalhou, como já se referiu, com o pintor flamengo, Francisco Henriques que de Flandres emigrou para Portugal, onde viveu até o fim de sua vida. Essa influência da escola flamenga ajuda a explicar, em alguma medida, que Vasco Fernandes tenha adquirido seus conhecimentos a partir dessa tradição da pintura e que tenha sido por ela influenciado a partir dessa relação de aprendizado com o mestre flamengo Francisco Henriques. Mas, sem termos de comparação, foi exatamente essa distância da pintura feita em Flandres, e em outras partes da Europa, que ao nosso ver, posicionou o pintor Vasco Fernandes nessa condição singular, diante da própria história que ajudou a construir e, exatamente por isso, seu trabalho nos faz tomar de espanto quando o conhecemos.
A marca flamenga no conjunto das pinturas do Grão Vasco, em Lamego, pode ter tido uma influência direta de Francisco Henriques, com o qual trabalhou na construção do Retábulo da Capela Mor da Sé de Viseu (1501-06), mas também se refere ao contato com outros artistas flamengos, que estiveram em Portugal e que trabalharam com ele nesse obra, nomeadamente, Arnão de Carvalho e João de Utrecht. Há uma outra questão que se coloca: a possibilidade de Vasco Fernandes ter conhecido, através das imagens em circulação naquela altura, obras de outros artistas flamengos mais conhecidos, entre eles, o próprio mestre de Bruges, Jan van $\mathrm{Eyck}^{2}$, pois não há registro que Vasco Fernandes tenha viajado para Flandres. Esta viagem para os Países Baixos, através de outras conexões, se denota pela capacidade do pintor se relacionar com a tradição flamenga de forma a se fazer presente a partir de sua própria lavra, uma pintura que, do nosso ponto de vista, é, em termos expressivos, superior inclusive ao que se conhece do próprio Francisco Henriques em Portugal.

Mauricius Martins Farina, A aura da presença em processos de deslocamento: nas ruínas do playground. 


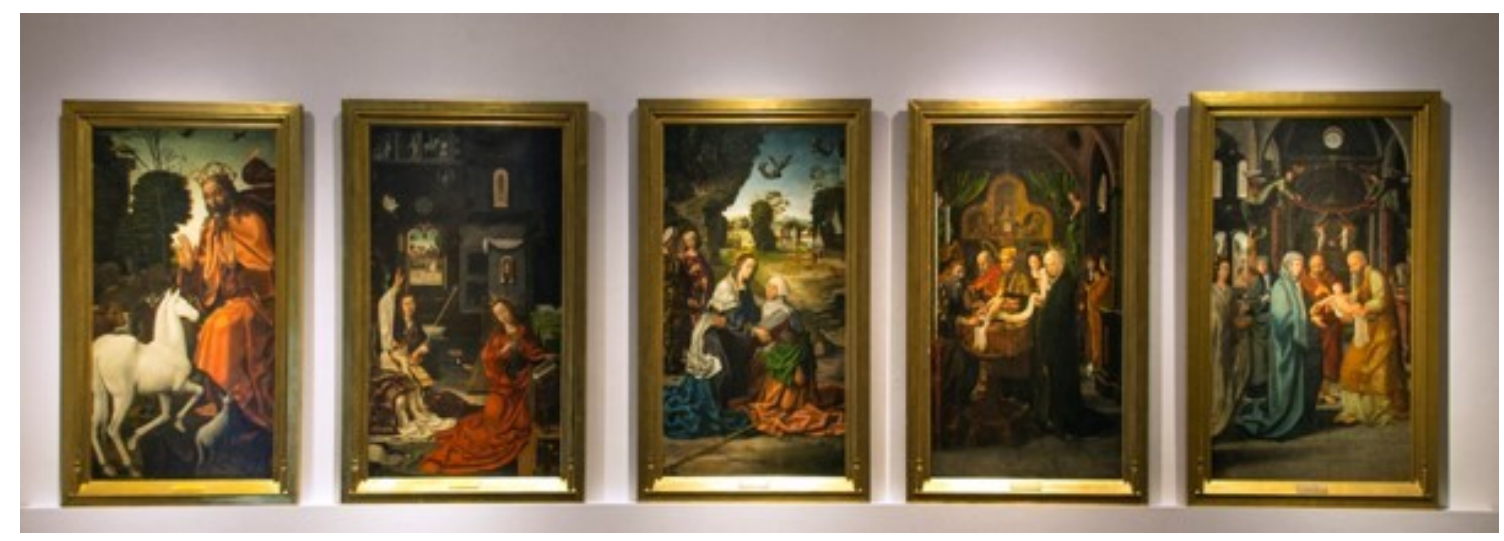

Fig. 1 - Vasco Fernandes, Retábulo da Sé de Lamego, 1506-1511.

pintura a óleo sobre madeira

Museu de Lamego,

(Foto: Mauricius Farina) 
A obra do Grão Vasco pode ilustrar o modo extraordinário como a pintura e os pintores provenientes dos Países Baixos meridionais marcaram a pintura ibérica. Não exatamente porque essa influência tenha sido mais profunda no seu processo ou porque a tenha assimilado de forma especialmente interessante. A este nível, pode dizer-se que não difere substancialmente dos pintores seus contemporâneos, pois a influência da matriz flamenga no gosto da clientela e no trabalho dos nossos pintores, coincidindo 0 seu auge com o fulgurante período manuelino, foi decisiva a ponto de provocar um muito expressivo fenómeno de descontinuidade. (RODRIGUES, 2007, p. 35)

A condição das imagens circulantes é algo que se registra a partir da influência da movimentação da cultura flamenga que naquele período se fazia notar em Portugal e na Espanha de maneira efetiva. Os cinco retábulos (1506-1511), que estão preservados no Museu de Lamego, são parte de um conjunto maior feito para a Catedral de Lamego, mas que se perderam no século XVII.

A relação da pintura portuguesa com a flamenga, sendo esta matriz daquela, é fundamental para enquadrar o trabalho de Vasco nesta fase inicial. Em primeira instância, essa relação passa pelo acu- tilante realismo da forma, tanto dos cenários de enquadramento e das figuras, cuja monumentalizada presença no primeiro plano, com gestos teatralizados, define 0 essencial da estrutura figurativa e narrativa da obra, como dos detalhes mais ínfimos, resultantes do mimético processo de transposição para a imagem da riqueza inesgotável das formas e dos detalhes do mundo visível. (RODRIGUES, 2007, p. 42)

Na tradição dos retábulos, o Retábulo de Gante, pintado em 1432 pelos irmãos Hubert e Jan van Eyck, é fundante. O Retábulo de Gante é reconhecido como uma conquista da pintura ocidental, em uma escala sem precedentes. As pinturas de Jan van Eyck são o resultado de um processo extremamente refinado, e no âmbito da tradição da pintura flamenga são, elas mesmas, uma matriz referencial. A relação entre descrição imanente e a fabulação metafísica, algo que distingue os pintores de Flandres do século XV da tradição pictórica que se instituía na Itália naquele mesmo período, tem fatores que serão determinantes para a arte descritiva dos Países Baixos no século XVII, assunto que reafirma as condições de uma espécie de matriz cultural do norte europeu, em suas derivas imanentes. 
Existem relatos que indicam a passagem de Jan van Eyck por Portugal e Espanha, mas para tratar de assuntos que não eram exatamente sobre pintura. Erwin Panofsky, em seus estudos sobre os "primitivos flamengos", relatou a passagem de Jan van Eyck pela Península Ibérica.

\section{[...] Felipe o Belo não só admirava a Jan van Eyck como grande artista, mas também confiava nele} como amigo e cavalheiro. Em 1426, data tão remota, o pintor empreendeu, em nome de seu senhor, certas peregrinações confidenciais e "viagens secretas", e durante os anos seguintes foi membro de duas embaixadas na Península Ibérica. Depois de dois casamentos anteriores, ambos finalizados pela morte, Felipe o Belo seguia sem herdeiro, e a primeira de duas viagens ao estrangeiro, que durou desde o começo do verão até outubro de 1427 (quando Jan van Eyck recebeu sua comenda de honra em Tournai), se empreendeu, segundo parece, para negociar um casamento com Isabel de Espanha, filha de Jaime Il, conde de Urgel. Tendo fracassado por razões desconhecidas, foi em outra missão a Portugal com o fim de obter a mão da fiIha mais velha do rei João I, também chamada Isabel. Desta vez os enviados tiveram êxito, ainda que ao preço de travessias extremamente duras e perigosas, que acabaram por ampliar o tempo com escalas dilatadas na Inglaterra em ambas as viagens. Partiram em 19 de outubro de 1428 e regressaram com a princesa apenas em dezembro de 1429, 0 casamento ocorreu em 10 de janeiro de 1430. (PANOFSKY, 2016, p. 180)

Há também um outro aspecto nessa passagem de van Eyck pela Península Ibérica, descrito por Manuel Parada López de Corselas no livro El viaje de Jan van Eyck de Flandres a Granada (1428-1429), onde se reconhecem, ainda, as marcas de uma influência mudéjar na pintura de Jan van Eyck. Corselas cita, em seu estudo, uma revisão da viagem a Espanha realizada por B. Fransen, segundo a qual, "Jan van Eyck deve ter ficado impressionado pelas novas paisagens, os trajes locais, os costumes, os produtos sulistas e as luxuosas festas da corte em Portugal"; ele diz ainda que, "possivelmente o pintor levava consigo um caderno de esboços durante a viagem". Isso se justifica, segundo ele, porque "a vegetação mediterrânea, a arquitetura e os azulejos valencianos de suas pinturas podem ter origem neste caderno". (FRANSEN apud CORSELAS, 2016, p. 34). Portanto, as relações de comunicação entre Flandres e a Península Ibérica se deram em uma via de mão de dupla, como explicam as relações políticas de herança entre coroas europeias 
no século $X V$, com o predomínio espanhol no século XVI.

A diversidade cultural da Península Ibérica naquele período, onde as influências mulçumanas, hebreias, cristãs e outras ainda mais antigas formatavam camadas multiculturais, está na base, nas etnias desse povo peninsular ibérico. $O$ fato reconhecido da conformação de uma supremacia cristã, a partir da expulsão dos mulçumanos e da conversão ou expulsão dos hebreus, que caracteriza a expansão do império espanhol em seu "século de ouro", permitiu considerar um predomínio da própria relação entre Igreja e o Estado, ou da influência da primeira sobre o segundo, o que pode ter sido uma instância de dificuldade para a investigação sobre os processos artísticos que ali se instalavam. Os documentos que restam, as encomendas, os contratos, se relacionam fortemente com o poderio clerical, particularmente em Portugal, destacando-se, nessa condição, um aspecto diferencial entre os povos do sul e os povos do norte europeu; estes, em seu apreço pela imanência, dedicaram uma maior importância à investigação da realidade, elementos de interesse para uma cidadania burguesa e mercantilista. Como exemplo dessa condição, pensamos na farta documentação que $E$. Panofsky pôde recorrer nos trabalhos que fez sobre os primitivos flamengos e sobre Albrecht Dürer, com uma base alimentada por uma vasta bibliografia.

Mas não podemos pensar, com relação aos trabalhos que Vasco Fernandes realizou no âmbito de sua regionalidade, que os documentos bibliográficos sobre ele sejam muitos e que estejam à disposição. Sobre o mestre de Viseu é preciso acentuar o importante trabalho de investigação empreendido por Dalila Rodrigues, reconhecida atualmente como a maior referência para um estudo sobre o artista, a partir de bases documentais mais efetivas que foram consultadas exatamente em espaços conservados pela igreja católica portuguesa ao longo desses séculos. Com todas as dificuldades documentais, o trabalho empreendido pela investigação de Dalila Rodrigues sobre o Grão Vasco é, de fato, fundamental para a revisão de muitos aspectos de sua biografia, suplantando interpretações e deduções míticas que se faziam sobre o artista.

Mauricius Martins Farina, A aura da presença em processos de deslocamento: nas ruínas do playground. 


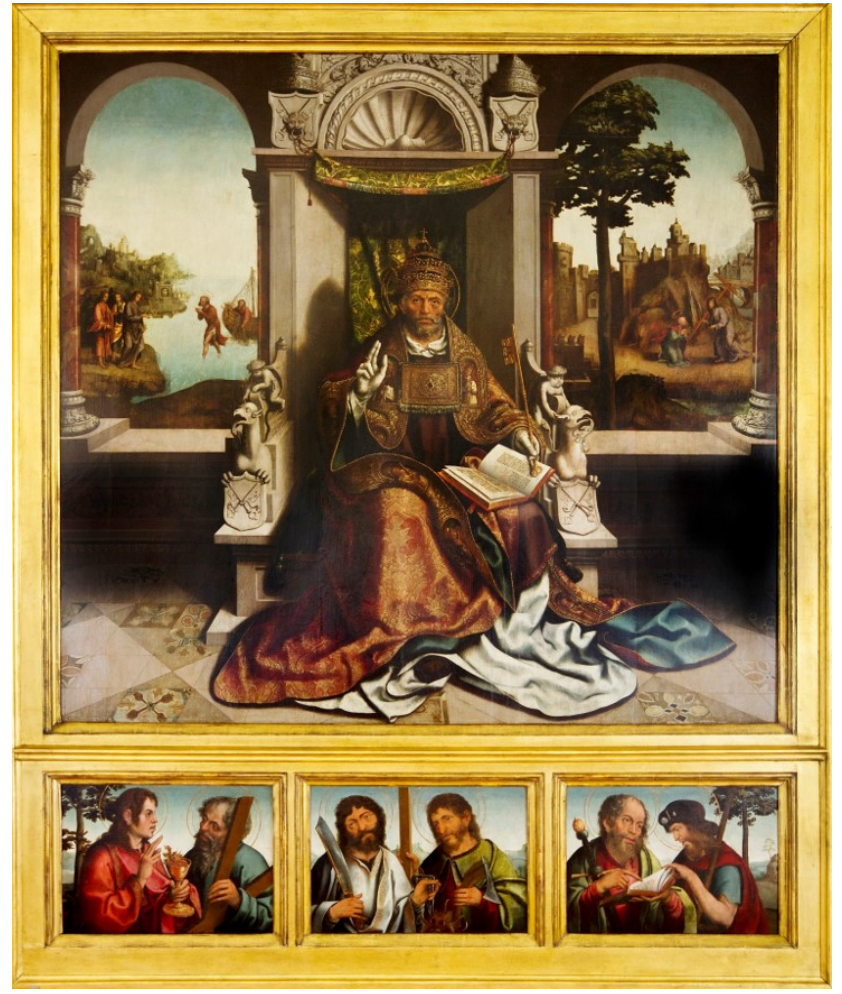

Fig. 2 - Vasco Fernandes, São Pedro, c. 1530.

óleo sobre madeira, $213 \times 213,3 \mathrm{~cm}$

(Fonte: http://www.museunacionalgraovasco.gov.pt/?p=229) 
0 que se conhece da biografia do Grão Vasco, e que é afinal muito pouco, permitindo-nos definir apenas algumas coordenadas para o seu percurso artístico. Através delas, e sobretudo por associação, é possível estabelecer algumas relações entre o cenário em que viveu, o perfil dos clientes que teve e a obra que realizou - ou pelo menos as pinturas que chegaram até nós. Pese embora o seu carácter residual e fragmentário, a obra é também um importante testemunho histórico. Diz-nos, antes de mais, que o seu autor beneficiou de uma conjuntura favorável e de um contexto particularmente estimulante em termos criativos. E que nesse contexto ficou marcado por dois momentos-chave: as reformas manuelinas das catedrais de Viseu e de Lamego na viragem do século XV para o século XVI; e a reforma renascentista promovida por D. Miguel da Silva, pelos anos de 1530, na mesma catedral viseense e na sua residência episcopal, na quinta de Fontelo. Estes dois acontecimentos têm, de facto, iniludível expressão na obra que realizou, configurando um período inicial mais estritamente flamenguizante, explicável no quadro das complexas realizações estéticas do manuelino e nas usuais parcerias entre artistas, e num período de mais expressiva modernidade, marcado pela abertura a soluções e modelos de derivação italiana e a pontuais referentes classicizantes. (RODRIGUES, 2007, p. 25)
Sobre a obra do pintor nessa fase em Lamego, onde se percebe uma clara deriva da sua fatura em relação ao que se fazia em Flandres desde o século $X V$, especialmente na relação entre o real descrito nos termos da plasticidade e o simbólico presente nas figuras, construído como esquema narrativo pela visualidade da composição, permanecem alguns detalhes de expressão que indicam para uma fase posterior de sua obra, alguns anos mais tarde, quando Grão Vasco se encontraria com a arte italiana. E nesse caso existe o registro de sua viagem para Roma, quando acompanhou o Bispo de Viseu.

Segundo nos informa sua mais atenta investigadora, "os documentos não nos dizem muito acerca da vida do mais famoso pintor português. Não nos dizem por exemplo, onde e quando nasceu, ou de quem era filho". (RODRIGUES, 2007, p. 11) E ela completa:

Muito mais simples e generosa em informações éa sua história mítica, que o dá nascido nas cercanias de Viseu, como sendo filho de um pobre moleiro e protegido de um bispo famoso. Desta história, iniciada no princípio do século XVII e consolidada já no quadro do Romantismo, em meados do século XIX, é possível extrair alguns dados e hipóteses interessantes. Fortemente ancorada numa tradição

Mauricius Martins Farina, A aura da presença em processos de deslocamento: nas ruínas do playground. 
local de impressionante densidade histórica, e apoiada na evidência visual das monumentais pinturas que fez para a sé e que aí se exibiram ao longo de dois séculos em diversas capelas, a história mítica é, antes de mais, um excelente testemunho das impressionantes ressonâncias que o pintor e a sua obra provocaram nos corredores do tempo. (RODRIGUES, 2007, p. 12)

A diversidade de elementos lacunares sobre a obra de artistas como Grão Vasco ajudou aqueles que estavam ideologicamente interessados em princípios nacionalistas para afirmar a originalidade dessas obras, independentemente de sua conexão com outras matrizes, ou de outra ordem, menosprezando sua importância, sendo esse um ponto de conexão que incluiu artistas oriundos de outros ambientes, como, por exemplo, no caso do mestre Aleijadinho no Brasil colonial, sobre o qual ainda há o que se pensar.

Ao reboque da construção de um pertencimento nacionalista para o artista, onde outros interesses, que não os da arte, estão a espreitar, é preciso reconhecer que com a obra de Vasco Fernandes localizamos uma experiência expressiva característica, marcada pela destacada capacidade inventiva em um cenário distante de facilidades. Dessa forma, a própria condição de um sentido erudito para a arte, da busca pela verdade a partir do artista, sobrepuja necessidades exteriores que a tornariam uma mera emulação. Com Grão Vasco temos um artista sobre o qual se reconhece muito mais que uma força de trabalho ou uma capacidade de pôr as coisas a bom termo. Sua produção material nos faz pensar sobre as relações distintas entre os centros hegemônicos da cultura e suas periferias, em suas relações geopolíticas, nas influências dessas viagens e na construção de uma história própria, de uma identidade motivada na relação de suas referências.

Entretanto, não situamos aqui a intenção de aprofundar uma descrição biográfica sobre o artista ou de investir em uma interpretação mais direta sobre a sua obra. O que nos interessa é, de fato, verificar que, apesar de uma condição cultural claramente subalternizada por um sentido de provincianismo típico de culturas que foram assentadas sob o manto secular da religiosidade cristã, em associação com um estado igualmente colonizador, representado pelo poder dos reis, como no caso da Península Ibérica, que a partir do século $X V$, estendeu seus domínios 
territoriais, grandes coisas foram feitas pelos artistas. Apesar dessa relação de encomenda relacionada a outros interesses, a arte sobrevive e sua experiência é de fato algo que se faz por uma outra camada de negociação com a vida. Nessa condição, a mitificação dos eventos históricos, através da mediação política ou religiosa, é também um fator que dificultou a construção da história como acontecimento memorial com farta documentação. Ainda assim, é preciso trabalhar com a história da arte tendo em questão aquilo que se expressa no corpo das imagens como uma condição de presença, algo que se faz a contrapelo do sentido imediato dos sentidos de uma aplicação de caráter doutrinário, seja da religião ou do Estado.

Desfavorecer a compreensão do tempo passado, tratando-o com um viés de oportunidades que podem não se explicar de forma evidente, pode transformar alguns artistas, como o próprio Grão Vasco, em sujeitos excêntricos destacados em sua própria cultura, como mitos, gênios da natureza humana que se fizeram ao acaso, e não pela potência de uma expressão singular que se conecta ao seu tempo, mas também à história, onde um número muito mais amplo de artistas podem se encontrar. Se olharmos apenas para os documentos, ou para uma história dos estilos, podemos deixar de perceber muitos elementos de importância para a montagem de uma outra história, mais factível, a partir dos sinais que estão marcados no corpo da obra, sendo ao mesmo tempo plasticidade e memória.

Movidos pelo singular de sua aparição, os artistas, sobre os quais pouco se sabe, em territórios mais afeitos às províncias, passam a ser absorvidos pela nacionalidade à qual pertencem, como personagens heroicas, figuras que servem sociologicamente como antídotos para aplacar o recalque de estarem em uma potência periférica que é subalternizada pelos centros hegemônicos.

Existem obras que, exatamente pelo contexto de influência, capacidade de emulação e utilização de modelos, se revelam como viagens feitas pela compreensão de um visto por gravuras, por desenhos, ou seja, através de cópias feitas a partir de um original que ao ser difundido por imagens reprográficas permite que se estabeleça uma conexão com o imaginário, através de complexa rede de comunicação dessas imagens. Existem outras, que com todas estas condi-

Mauricius Martins Farina, A aura da presença em processos de deslocamento: nas ruínas do playground. 
ções, ainda apresentam a possibilidade de acrescentar ao imaginário alguma novidade. Mas muitas destas experiências de emulação não estão à altura de um diálogo possível com suas referências originais e atuam como meras cópias de estilo, por isso não sobrevivem ao tempo.

Definitivamente esse não é o caso de Vasco Fernandes que, pelas condições de sua aparição, explicitou a presença de um deslocamento de origem, acentuando uma potência expressiva materializada em pinturas que o tornaram algo mais que um artífice de boa capacidade, como um artista cujas imagens anteciparam um apreço pelo realismo distraído em iconografias religiosas e mais pela potência de sua expressão nas imagens. É possível supor, por essa condição de conhecimento descritivo da luz, que as pinturas do Grão Vasco estão, de fato, entre as mais importantes que se tenham realizado na Península Ibérica no século XVI.

\section{O tempo como presença nas dobras mineiras}

Quien aspire a hacerse con una de las claves maestras que permiten la explicación y esclarecen el carácter del arte español, búsquela en Portugal. La mitad de sentido recóndito de nuestra historia espiritual, de Portugal fluye. ¿Qué digo, de la nuestra? De la europea, probablemente. Alguna vez, me he atrevido a aventurar que, en este compuesto designado con el nombre de Cultura, Europa únicamente presentaba al análisis riguroso dos cuerpos simples: Grecia y Portugal. El resto es tal vez cuestión de dosis. (D'ORS, 2015, p. 125)

A partir de Antônio Francisco Lisboa, autor de uma obra reconhecida como um patrimônio cultural, e tendo ainda em questão as experiências da pintura do Grão Vasco em sua contingência, consideramos o que disse Eugenio D'Ors sobre o barroco, e sua matriz portuguesa, como uma possível condução para um processo de de contiguidade cultural que, por evidências históricas não tão evidentes, pode também ter repercutido nas Minas Gerais a partir do ciclo do ouro no século XVIII. Segundo D'Ors, Portugal ofereceu um arquétipo do barroco quando sua arte, no século $X V$, permitiu uma superação da paixão sobre a razão, ou seja, apesar do apreço pela descrição das aparências, possuía uma sofisticação sensível guiada pela emoção. Uma distinção inclusive em relação à Flandres, que se destacou pela influência naturalista. 
O conceito alargado de barroco, proposto por Eugenio D'Ors, que estabelece relações culturais que distinguem Portugal na Europa como uma matriz, vincula-se à possibilidade de condução de uma espécie de aura onde expressões de "alma" e de "emoção" são descritas a partir de experiência relatada em terras portuguesas. Mais especificamente, em Tomar, onde percebeu uma atmosfera de sentido que o levou a considerar, por exemplo, que haveria um fio condutor entre o mítico pintor português do século XV, Nuno Gonçalves, e Diego Velásquez no século XVII espanhol. Nesse diálogo, poderíamos retomar a obra do Grão Vasco, que se situa na passagem dos acontecimentos entre um e outro.

Algo distante no tempo e no espaço, mas sobre a influência dessas possibilidades, nasceu, na cidade Ouro Preto em 1737, Antônio Francisco Lisboa, segundo os estudos de Marcos Paulo de Souza Miranda (2014), que descobriu a certidão de batismo do mestre mineiro, alterando a data de 1738 que, por sua vez, havia substituído a primeira atribuição: 1730. Esse estudo atualiza e, ao mesmo tempo, atesta a origem de Antônio Francisco Lisboa. É de se destacar que, por várias razões, a própria existência do mestre foi questionada, ou ainda, diluída por alguns comentadores, nos termos de um trabalho que não seria dele, mas coletivo, e que a sua figura seria um mito construído para a exaltação de uma certa brasilidade mulata. Todas estas questões são parte da história desse personagem. Entretanto, não se pode ocultar os sintomas de uma fisionomia singular que está marcada no conjunto da sua obra.

Sobre o mestre mineiro ainda existem muitas incertezas, o que se demonstra pela tradicional dificuldade documental que, como em Grão Vasco, se refere ao trato e no interesse específico sobre a história de seus mestres de ofício.

O desconhecimento e a falta de documentos de atestação são característicos de tantos outros artistas, como também de mestres portugueses de séculos anteriores, como o próprio Vasco Fernandes, ou ainda, Nuno Gonçalves, um personagem sobre o qual não se sabe muita coisa e, ainda que sobre ele existe certa desconfiança, inclusive, de que tenha existido. Os Painéis de São Vicente de Fora, a ele atribuídos, que estão no Museu Nacional de Arte Antiga de Lisboa, podem não ter sido pintados por ele, mas por algum

Mauricius Martins Farina, A aura da presença em processos de deslocamento: nas ruínas do playground. 
artista estrangeiro, a pedido da rainha de Portugal. Entretanto, tudo isso fica em um terreno difícil, onde a história se transforma em um jogo de atribuições e o fato é que esse conjunto de obras é reconhecido como obra de Nuno Gonçalves. Aliás, se assim não for, certas ideias de Eugenio D'Ors ficam comprometidas.

Voltando a Antônio Francisco Lisboa, lembramos que era filho de Manoel Francisco Lisboa e, portanto, descendente de uma família ligada ao ofício das construções e das talhas em pedra e madeira desde gerações, em Portugal. Sua mãe era escrava e se chamava Izabel. "Propriedade" de Manoel Francisco Lisboa foi alforriada. Sobre ela as informações são mínimas, mas o seu papel na história do filho certamente não é pequeno. Contam que nas Minas Gerais do século XVIII não havia muitas mulheres brancas, assim, a quantidade de mulatos nascidos naquelas circunstâncias foi muito grande e com muitas consequências na cultura brasileira, do povo negro e de seus descentes, em busca de um lugar no país.

É importante destacar que foi através de seu pai, e por interferência dele, que Antônio Francisco Lisboa pôde conseguir alguma consideração, aprender o seu ofício e de- monstrar suas habilidades. Além disso, essa condição de pertencer a uma família de mestres de ofício ligada às artes, emigrada de Portugal, é algo que está em sua genética, além, evidentemente, das heranças de matriz africana pelo lado materno. Essa condição nos auxilia para demonstrar que sua obra não foi uma manifestação autóctone, ou a força de um "milagre divino" que se ergueu a partir da "genialidade" daquele "gênio mulato". A ideia de uma nova arte, genuína e brasileira a partir dele, foi uma imagem reforçada pelos modernistas paulistas, quando a arte mineira, que desde o final do ciclo do ouro ficou esquecida por entre as montanhas, guardada em seu provincianismo, foi redescoberta pelos viajantes. É fato que Antônio Francisco Lisboa realizou muitas obras em escultura e arquitetura e foi responsável pela direção de várias equipes, que incluíam outros tantos artífices. Essa sua obra, desde muitas décadas, está consagrada e destacada entre aquelas que foram fundamentais para a consagração de Ouro Preto como uma cidade patrimônio cultural da humanidade, mas também é fato que tudo isso se liga a eventos muito anteriores. 
A cidade de Ouro Preto, antes Vila Rica, foi fundada em 1711 a partir de outras vilas que nasceram no caminho das bandeiras na busca pelo ouro e pelas pedras preciosas. Uma herança que constituiu uma história complicada, porque além das riquezas, e em sua causa, muito sangue foi derramado e populações nativas foram destruídas. Os registros da riqueza transferida a partir daquela cidade, no século XVIII, dão notícia que mais de 800 toneladas de ouro foram enviadas para Portugal. E mais ainda, que naquela altura, a cidade de Ouro Preto chegou a ter mais de 40.000 habitantes, o que para a época era muita coisa. Destaque-se que nessa leva de emigrados desde Portugal, muitos teriam vindo da região norte, nas regiões do Minho e da Régua, algo que curiosamente liga os territórios provinciais de Vasco Fernandes, onde se tinha uma série de costumes culturais que acompanharam esses emigrantes, até o Brasil.

\section{0 culto às Almas na Península Ibérica assumiu uma amplitude de invocações semelhante àquela ob- servada por Vovelle na França, Galícia e Itália, no tocante às bases antropológicas alargadas, a u uso de peditórios (bacia e cofre das almas) para os su- frágios, sua longa duração e mesmo ao padrão de representação. Tem semelhanças, mas também é}

assaz específico por não se restringir ao recinto religioso, dominando amplamente 0 exterior nos núcleos urbanos e meio rural, sobretudo na região Norte, entre o Minho e o Douro, justamente de onde vem boa parte dos povoadores das Minas Gerais. (CAMPOS, 2013, p. 57)

A partir da constatação que a partir dos fluxos migratórios as viagens estabelecem camadas de um complexo imaginário, derivado de suas matrizes culturais, a obra produzida por Antônio Francisco Lisboa não pode ser instituída apenas nos marcos de um país em formação, mas, mais do que isso, ela surge como uma consequência desses hibridismos. Assim, a consagração desse artista, mulato, com problemas físicos que the valeram a alcunha de "Aleijadinho", como o representante mais visível de uma produção artística do Brasil colonial, será aclamada por várias razões, mas nem todas elas correspondentes ao fato que sua potência artística se acentuar a partir de um diálogo efetivo com outras matrizes culturais que foram para ele fonte de investigação, mas para as quais não se submeteu como mero reprodutor de estilos. Suas obras, de fato entre as mais singulares já construídas fora da Europa, sua correspon-

Mauricius Martins Farina, A aura da presença em processos de deslocamento: nas ruínas do playground. 
dência formal, ainda que no período em questão fosse o rococó, não eram derivadas de uma direta correspondência com o que se fazia em França e mesmo, anteriormente, com o sentido de barroco que nasceu na Itália, significando uma "pérola imperfeita" e em oposição ao clássico. Há nelas, mais do que isso, uma solução encontrada no próprio terreno, na escolha da pedra sabão ou nas soluções que se podiam oferecer naquele lugar.

Consideramos que o trabalho de Antônio Francisco Lisboa estava de fato impregnado daquele sentido previsto para um barroco português, afetado pelo drama, teatralizado pela religiosidade católica, pela luz tropical, afetado por uma emoção que ultrapassa a razão, como disse Eugenio D'Ors. Uma obra fundamentalmente vigorosa e híbrida, ainda quando se reconhece a presença das rocálias e de uma simplificação de pesos cromáticos que nos conduzem a pensar na ideia de uma influência do rococó, entretanto, pelas condições dessa correspondência, pelo visto em estampas. Os feitos do "mestre Aleijadinho" demonstram-se materialmente conectados com a tradição especular e dramática que se fez notar no barroco ibérico, com alguma influência italiana, coisa que se sabe já estava presente em Portugal e se reflete no Brasil colonial, desde a influência Pombalina e mais, com traços de um ambiente influenciado pelo flamejante que soube sobreviver no imaginário daqueles que se lançaram ao mar para "fazer a América" e que ainda guardam essas heranças manuelinas.

O mestre Antônio Francisco Lisboa soube viajar nos livros e na vida para compor sua obra, sem nunca ter saído do Brasil, mas, é fato que se diga, faz parte de uma linhagem de mestres que desde Portugal migraram para o Brasil. A partir de obras vistas em livros ilustrados, conheceu algumas experiências em escultura e arquitetura que vinham da Europa. Uma viagem sem deslocamento, um conhecimento sem a presença. Muitos debates se relacionam ao homem Antônio Francisco Lisboa desde que seu trabalho foi homologado de modo romântico por Rodrigo José Ferreira Bretas, em texto publicado em 1858 no Correio Oficial de Minas Gerais. O Aleijadinho de Bretas é uma construção literária onde o gênio mulato da arte mineira, o artista aleijado que se associa ao monstruoso e ao sublime, algo que em um esforço político pretendia construir o monumento de um heroico nacional. Em livro intitulado $O$ Aleijadinho e $o$ 
aeroplano, a pesquisadora Guiomar de Grammont apresentou elementos para desconstruir o mito idealizado por Bretas e pelos modernistas, em relação a Antônio Francisco Lisboa. Grammont revelou circunstâncias importantes sobre as viagens que geraram as tais redescobertas sobre a arte colonial das Minas Gerais, primeiro o discurso dos viajantes estrangeiros no século XIX, que maravilhados com o exotismo do Brasil colonial informaram a Europa e depois, os modernistas de São Paulo, entre ele Mario de Andrade, que estavam implicados na construção de uma atmosfera nacionalista para a cultura brasileira.

Após ter despertado, no século XIX, tanto interesse nos viajantes estrangeiros, Minas Gerais caiu no esquecimento devido ao esgotamento das minas de ouro e diamante, e sua arte sofreu a mesma sorte, durante quase um século. Em 1922, a Semana de Arte Moderna foi organizada por um grupo de intelectuais de São Paulo. Seu objetivo essencial era descobrir as assim chamadas raízes da alma brasileira, e foi e Minas Gerais e à arte do mulato que esses intelectuais fizeram apelo para construir uma primeira criação artística nacional. Esse projeto tem suas raízes nas primeiras viagens de Mario de Andrade a Minas, a partir de 1917.
Teria havido, portanto, um longo intervalo de esquecimento entre essas duas viagens de "descoberta" da arte mineira "colonial" - a dos modernistas no início do século XX. (GRAMMONT, 2008, p. 133)

Antônio Francisco Lisboa tem muitas histórias em torno de si, entretanto, as dúvidas sobre a autoria de suas obras, ainda que se exagere em número, potencializam sua figura, mas não podem eclipsar o que se fez construir como uma forma singular, talhada em madeira e pedra sabão. Deslocar-se às outras cidades do período colonial das Minas Gerais além de Ouro Preto, é algo que se coloca como uma viagem necessária para o reconhecimento dessas circunstâncias artísticas e de faturas amplamente conectadas com a tradição especular e dramática impactada por uma influência intertextual do barroco ibérico e italiano. Assim como é igualmente importante deslocar-se até as cidades de Lamego e Viseu, para o reconhecimento, em presença, da impressionante obra do pintor Grão Vasco. Curiosamente, tanto em Grão Vasco quanto em Aleijadinho, notamos certo problema em relação ao zeitgeist dos grandes centros artísticos europeus, algo que se estabelece com

Mauricius Martins Farina, A aura da presença em processos de deslocamento: nas ruínas do playground. 
a distância de um século em cada um, o que reforça a questão dos modelos.

Para os pesquisadores que admitiram a existência do Aleijadinho - é claro que devidamente colocado no pódio como o maior artista do periodo colonial no Brasil e, talvez, de todos os tempos -, um dos mais apaixonantes problemas passou a ser a "originalidade". A questão se encontra intimamente relacionada ao tema do autodidatismo do artífice e ao fato realmente espantoso da concentração de tantas obras, em um tempo tão exíguo, num lugar com tantas dificuldades de acesso como as Minas Gerais do século XVIII. Hannah Levy foi a primeira pesquisadora a levantar a hipótese do uso e modelos das gravuras europeias de Bíblias ilustradas da época na pintura de Manoel da Costa Ataíde, o que significou verdadeira revolução nos estudos sobre o chamado "barroco mineiro". (GRAMMONT, 2008, p. 251)

De modo contrário, ao fetichismo viajante que em sua passagem se pretendeu à conquista de souvenires, a condição de um turista vitimado pela ausência de si não é nova e nem mesmo o fato de sermos embriagados por falsos arquivos, onde criamos fantasias que não são, de fato, história. Aquilo que propomos como viagem se faz em direção à experiência dos artistas, porque são eles que se oferecem ao outro, nas obras, ainda que, nas camadas superpostas pelo tempo, novas possibilidades sejam evocadas. A experiência que essas obras evocam se distingue entre as brumas da modernidade, desde alguns séculos, e se preconiza com a distinção de uma suposta civilidade que faz de si o lugar como centro, e do outro, esse exótico, que pretende colonizar, seja pelo consumo ou de uma constante necessidade de sobrevivência ideológica.

Os países exóticos como eram então chamadas as colônias, exerciam uma enorme atração. As elites dominantes tinham a oportunidade de comprovar "ao vivo" esse exotismo. Outros, de menos poder aquisitivo, ou não podendo ou não querendo viajar, liam as façanhas nos livros de viagem. Essa é, sem dúvida, uma das explicações para 0 grande sucesso desse tipo de obra publicada na Europa do século XIX. No discurso modernista, o movimento é contrário: a ordem é revalorizar a arte local para integrá-la no vasto programa de "redescoberta" das raízes da arte brasileira, enfatizando aspectos com a miscigenação racial e cultural, projeto no qual foi integrado o mito do Aleijadinho. 0 que chamamos "redescoberta", contudo, em nossa perspectiva, significou, efetivamente, a invenção de um país que é 0 Brasil modernista, baseado na invenção das raízes culturais. 0 barroco teria um papel fundamental na constituição dessas "raízes".

(GRAMMONT, 2008, p. 134) 
Entre diversas obras do mestre Antônio Francisco Lisboa, a Igreja de São Francisco, em Ouro Preto, e o conjunto de peças em madeira policromada que está em Congonhas do Campo, próximo aos profetas do Santuário de Bom Jesus de Matosinhos (presença do norte de Portugal mais que evidenciada), são exemplos de obras que resultam de uma colaboração de Antônio Francisco Lisboa com Manoel da Costa Ataíde (1762-1830), o mestre Ataíde, cuja presença se destaca como a mais importante e influente para a pintura das Minas Gerais naquela época.

O mestre Ataíde foi o responsável pela pintura do teto da Igreja de São Francisco em Ouro Preto e, nessa obra, se destaca a presença de um "segundo céu espiritual", dobra conceitual que problematiza a fundação rococó como um mero estilema, reconhecendo uma movimentação tipicamente barroca. A policromia do conjunto de esculturas em madeira realizada por Antônio Francisco Lisboa como representação das cenas da paixão de Jesus Cristo foi feita pelo mestre Ataíde. Curiosamente, a presença de elementos identitários de uma cultura mulata, que estão presentes nas figuras desenhadas pelo mestre Ataíde, não são, afinal, obras de uma artista mulato, como se pode inferir de primeira investida, uma vez que o mestre Ataíde, afinal, era branco e filho de um capitão português. Estas obras representam a configuração dessa presença realista que se emociona na pintura desde Michelangelo na Capela Sistina, ou nas figuras de Caravaggio. Em outra condição, onde essa ideia de uma matriz portuguesa de cultura que se pode ver em Vasco Fernandes e em pintores e escultores ibéricos distinguidos pelo século XVII, todas essas camadas de cultura repercutiram nos mestres mineiros. As viagens, desde as estampas ou das matrizes culturais que podem correr nas "almas" como se pode pensar em uma antropologia dos deslocamentos, configuram, à sua maneira, a presença daquela realidade forçosamente interseccionada pela presença de novas identidades.

Mauricius Martins Farina, A aura da presença em processos de deslocamento: nas ruínas do playground. 


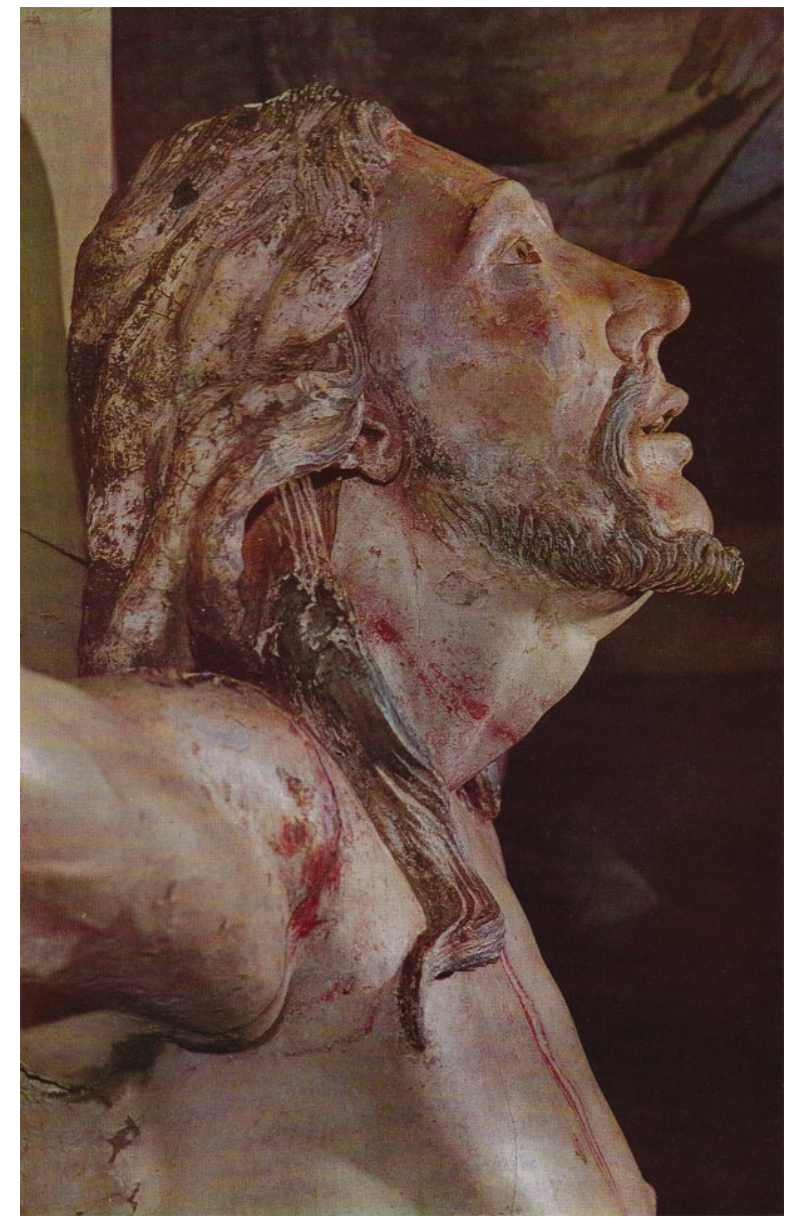

Fig. 3 - Antônio Francisco Lisboa, Cabeça de Cristo da Colocação na Cruz,

"Via Crucis" do Santuário do Bom Jesus em Congonhas do Campo, Minas Gerais (Fonte: BAZIN, Germain. O Aleijadinho e a escultura barroca no Brasil. Rio de Janeiro: Record, 1971, p. 237) 
Notas

${ }^{1}$ Um país que ainda não se livrou dos fantasmas de sua própria ignorância a respeito de sua própria origem e demarcação cultural e que, vez ou outra, como agora, vê espectros de uma governança insólita se insinuar em nome de um patriotismo de fachada, uma vez que é subserviente a outros impérios. Apesar disso e dessas heranças, o conhecimento científico e artístico que produzimos é fundamental.

2 Jan van Eyck, entre 1428-29, foi a Portugal para acompanhar a infanta Isabel, filha de João I à Flandres, onde desposou Filipe, o Belo. (CORSELAS, 2016, p. 22)

\section{Referências}

CORSELAS, Manuel Parada López de. El viaje de Jan va Eyck de Flandres a Granada (1428 -1429). Madrid: Ediciones La Ergástula, 2016.

GRAMMONT, Guimar de. Aleijadinho e o aeroplano: o paraíso barroco e a construção do herói colonial. Rio de Janeiro: Civilização Brasileira, 2008.

MIRANDA, Marcos Paulo de Souza. O Aleijadinho revelado: Estudos históricos sobre Antônio Francisco Lisboa. Belo Horizonte: Fino Traço, 2014.

PANOFSKY, Erwin. Los primitivos flamengos. Madrid: Catedra, 2016.

RODRIGUES, Dalila. Grão Vasco. Lisboa: Alétheia, 2007. 